\author{
Military Technical College \\ Kobry Elkobbah, Cairo, \\ Egypt.
}

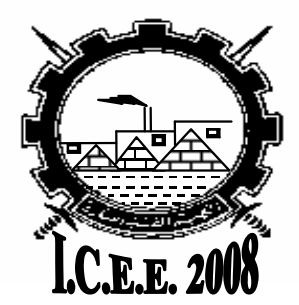

$4^{\text {th }}$ International Conference On Chemical \& Environmental Engineering

27-29 May 2008

\title{
STUDYING THE EFFECTS OF THE PERCENTAGE OF DIFFERENT TYPES OF FUEL AND BINDER ON DECOY FLARE PERFORMANCE.
}

\author{
HAWAS*. E. A; MOSTAFA* E. H. ; ISMAIL*. M. M.
}

\begin{abstract}
IR guided missiles pose the major threat to military aircrafts. Pyrotechnic decoy flares are still the most commonly used passive countermeasures for heat seeking missiles. Such flares require rapid burning rate and very high output radiant intensity values. Metal /Teflon compositions as $\mathrm{Mg} / \mathrm{Teflon}$ are highly energetic materials sufficient to produce high flame temperature and high spectral radiant intensity that enables these compositions to protect aircrafts from threat of IR guided missiles. In this study, thermochemical calculations were carried out for certain decoy flare compositions to predict the thermal radiation characteristics and the over all performance of such compositions. The study focuses on investigation the flame temperature of number of selected types of metallic fuel (Mg, Al, B and Ti) of different metal percentage $(10 \%-$ $80 \%$ ). Different types of binders [(viton) as energetic binder and (polyurethane) as moderate energetic binder] were examined with different percentage $(1 \%-9 \%)$. In the study Equilibrium Specific Impulse (Isp) was used to calculate the flame temperature based on formula of the elements, density, and heat of formation. Metal/Teflon compositions gave the highest flame temperature which means high burning rater at metal percentages $(30 \% \mathrm{Mg}, 30 \% \mathrm{Al}, 40 \% \mathrm{Ti}$ and $10 \% \mathrm{~B})$. The other results show that energetic binder (viton) is preferable to use in compositions rather than moderate energetic binder as polyurethane because it maintain the high flame temperature and burning rate as the percentage increase at pressure $1 \mathrm{~atm}$. Two values of operating pressure (0.5 - 1atm) have been examined to study the effect of pressure at different altitudes during the aircraft flight on the decoy flares flame temperature.
\end{abstract}

\section{KEY WORDS}

Pyrotechnics, Decoy flares, Radiant intensity, Passive counter measures.

\author{
NOMENCLATURE \\ MTV Mg/Teflon/Viton \\ IR Infrared
}

\footnotetext{
Egyptian Armed Forces
} 


\section{INTRODUCTION}

Pyrotechnic compositions can be considered as material capable of combustion when initiated by various impulses. These compositions should burn not detonate and provide special effects such as heat, light, smoke, and sound ${ }^{[1]}$. An important application of pyrotechnics is decoy flares which represent the major counter measure to military air- crafts against IR guided missiles.

Reports from theatres in Afghanistan, and most recently former Yugoslavia have shown that especially MANPADS (man portable air defense systems) such as the IR guided Stinger (FIM-92B/C), Strela (SA-7, -9, -13, -14), and Igla (SA-16, -18, -26) missiles are the most effective weapons to kill low flying aircraft and helicopters ${ }^{[2]}$. Recent analysis of operational data over a period of 25 years (19731997) showed that over $51 \%$ of 1434 military aircraft fatalities had fallen victim to infrared IR- guided air-to-air or surface-to-air missiles. The development of second (discriminatory) and third (imagery)-generation missile seekers put more responsibility on the IR countermeasure (CM) community to develop effective decoys to keep up with the advances in seekers technologies. However passive off-board countermeasures remain the main effective in-service technology against IR guided missiles. Among the recent development the "kinematic flares", "special materials", and the "thrusted expendables" decoys ${ }^{[3]}$.Stages will then be used to construct view models to predict the thermal radiation characteristics and the overall performance of generic pyrotechnic compositions.

The present study focuses on investigating the thermochemical properties (flame temperature) of a number of (Magnesium-Boron-Aluminum-Titanium)-Teflon-Viton compositions, similar to those used in Defense applications. Different types and percentage of binder such as viton as high energetic binder and poly urethane as moderate energetic binder are studied. Also the operating pressure have been examined. In addition a comparison of the flame temperature for all metal/Teflon and all percentage and types of binder and different operating pressure was performed.

\section{DECOY FLARES}

IR guided missiles are the most effective weapons to kill low flying aircraft and helicopters. To counteract this threat, pyrotechnic infrared decoys were developed as early as infrared missiles became available in the late 1950s. Such decoy flares require high radiant intensity which must be larger than aircraft. Also, Decoy flare is consequently an emitter of radiation in such spectral band with high energy level of radiation.

For designing decoy flare as passive counter measure it must satisfy one or more of the following items

- $\quad$ Higher energy than that of the target in the same spectral band.

- $\quad$ Radiation of confusing wave forms in the same spectral band ${ }^{[4]}$.

Today pyrotechnic decoy fares are still the most commonly used passive countermeasures to lure away the incoming heat seeking missiles. Their broad 
application can be attributed to ease handling, reliable probability of target rejection and available constituents such as metallic fuels and oxidizers ${ }^{[2]}$.

\section{COMPOSITIONS OF DECOY FLARES.}

In most cases pyrotechnic composition consists of fuel and oxidizer together with other additives required. The fuel is usually powdered elements, either metals or non metals as when oxidize provide heat energy. Metal /fluorocarbon- pyrolant systems (MFP) are high energetic materials which often comprise from Teflon (poly tetrafluoroethylene) $\left(\left(-\mathrm{C}_{2} \mathrm{~F}_{4^{-}}\right)_{\mathrm{n}}\right)$ as the main fluorine source mainly blended with Viton (hexafluoropropylene and vinylidene fluoride copolymer) $\left(\left(-\mathrm{C}_{5} \mathrm{H}_{2} \mathrm{~F}_{8^{-}}\right)_{n}\right)^{[4]}$. The metal /Teflon compositions especially $\mathrm{Mg} / \mathrm{Teflon}$ are high energetic composition which produce high combustion temperature so these compositions can be used as infra red decoy flare ${ }^{[5]}$. Pyrotechnic composition in powder forms are normally mixing and pressing into pellets or mold. Binder may be natural waxes, oils or resins, or manmade compounds which is used to coat and protect reactive component as metal from reaction with oxygen or humidity. It also modify the burning rate and so the performance of pyrotechnic composition ${ }^{[1]}$.

\section{THERMO CHEMICAL CALCULATIONS.}

Ignoring the influence of the air on the combustion of the compositions and using Chemical Equilibrium Specific Impulse (Isp) Code which calculate flame temperature based on the chemical formula of the elements, density, and heat of formation ${ }^{[7]}$.

\subsection{Combustion characteristics for different types and percentage of metal/Teflon compositions.}

Thermo chemical calculations were carried out for different types of metal /Teflon Niton compositions(table1). Compositions ((Mg/Teflon/Viton), (B/Teflon/Viton,), (Al/Teflon/Viton), (Ti/Tefl-on/Viton)) were studied to determine the effects of the kind of metal fuel on flame temperature Also the percentage of fuel which determine the ratio between metal fuel and Teflon. These varieties between metal fuel and Teflon enable us to predict the maximum adiabatic flame temperature that represents a good indication for spectral radiant intensity.

\subsection{Combustion characteristics for different types and percentage of binder based compositions.}

Thermochemical calculations were carried out for different percentage of binder to the candidate fuel based compositions which were expected to produce the highest flame temperature. Another calculations for two types of binder as viton which represent high energetic binder and polyurethane which represent moderate energetic binder for $\mathrm{Mg}$ with determined percentage of binder. These different compositions produce different adiabatic flame temperature which give a good 
prediction for spectral radiant intensity and the ability of the compositions to be uses in decoy flare.

\section{RESULTS AND DISCUSSIONS}

\subsection{Flare compositions with Different percentage and types of fuel metal.}

The relation between the calculated adiabatic flame temperature and the percentage of metal fuel as (Mg, B, A, Ti) are shown in fig. 1 The percentage of viton is constant for all compositions (5\%) and percentage of metal and Teflon is (95\%) The percentage of $\mathrm{Mg}$ is changed from $10-90 \%$. The Calculation were carried out with an assumption of $1 \mathrm{~atm}$ pressure.

The maximum adiabatic flame temperature is $3220 \mathrm{~K}$. These values are obtained when percentage of $\mathrm{Mg}$ is $30 \%$. Adiabatic flame temperature are increased till it reach the percentage $30 \%$ of $\mathrm{Mg}$ then it decreased as we can identified the correct ratio that produce the correct stochiometric for $\mathrm{Mg} / \mathrm{Teflon}$ reaction.

In order to identify the effect of metal with Teflon on the thermo chemical properties. many calculations with different metal were performed. Adiabatic flame temperature is shown in fig 1. The metal titanium (Ti), boron (B), Aluminum ( $\mathrm{Al}$ ), are used at pressure of 1 atm. The maximum adiabatic flame temperature of boron based composition is $3033 \mathrm{~K}$ that is obtained when percentage of $\mathrm{B}$ is $10 \%$. Flame temperature of $\mathrm{Al}$ is little higher than of boron which reaches $3525 \mathrm{~K}$ at the percentage $30 \%$. The maximum flame temperature of (Ti/Teflon) compositions is higher than the previous metal which reach $3625 \mathrm{~K}$ when percentage of $\mathrm{Ti}$ is $40 \%$.

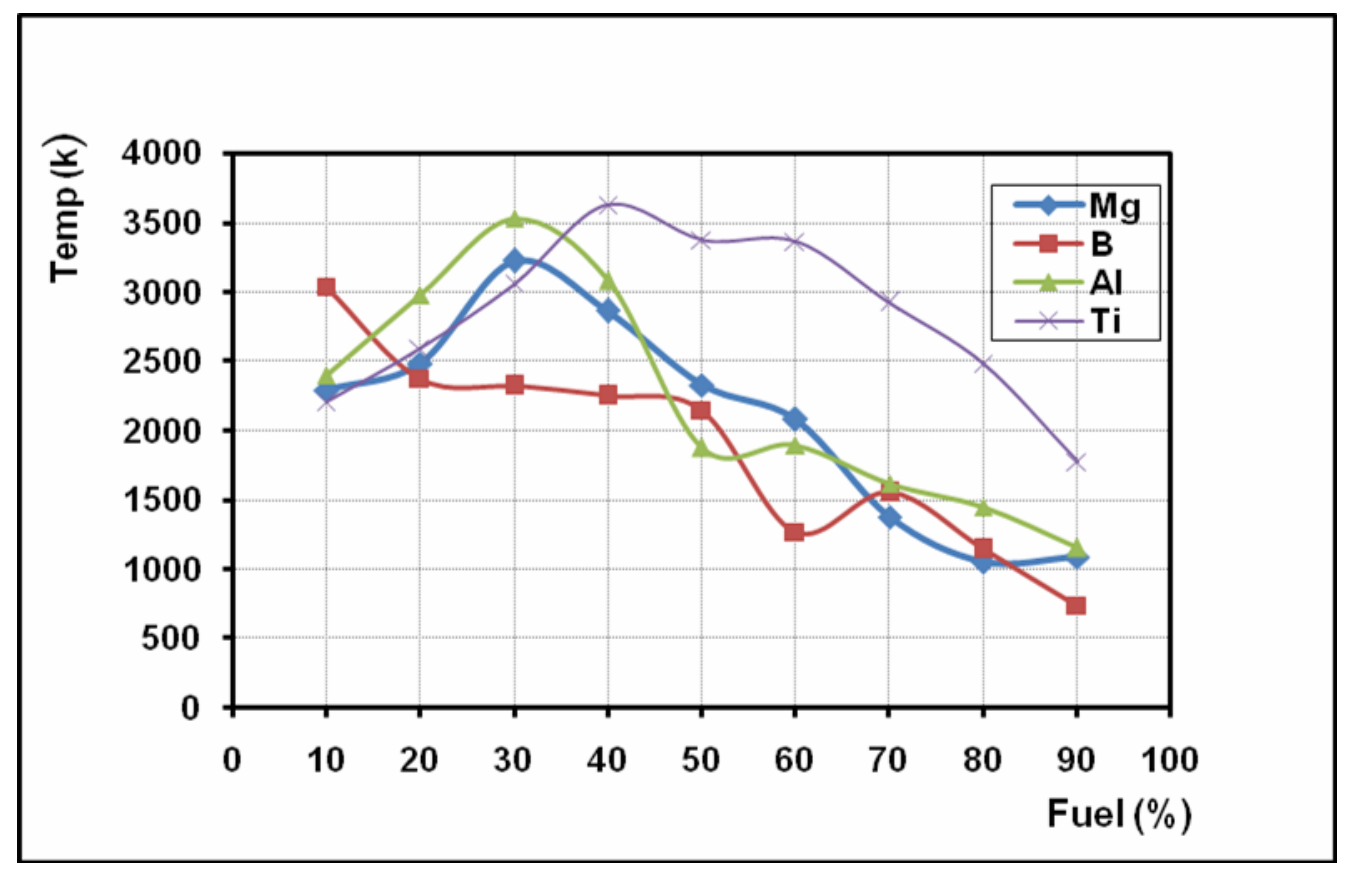

Fig.1. Effect of types and percentage of fuel on flame temperature. 


\subsection{Flare compositions with Different type of binder.}

The relationship between adiabatic flame temperature and the binder type is shown in fig.2. The percentage of viton was constant, $5 \%$, weight percentage for all compositions. The two types of binder gave different flame temperature during combustion. Compositions using viton produce high flame temperature rather than compositions applying polyurethane as a binder. These is because viton is classified as high energetic binder and poly urethane classified as moderate energetic binder. According viton is preferable to be used in decoy flare because the high flame temperature obtained produces fast burning rate that will cause minimum heat loses during combustion in the air at high altitude with high speed of ejection during aircraft escape.

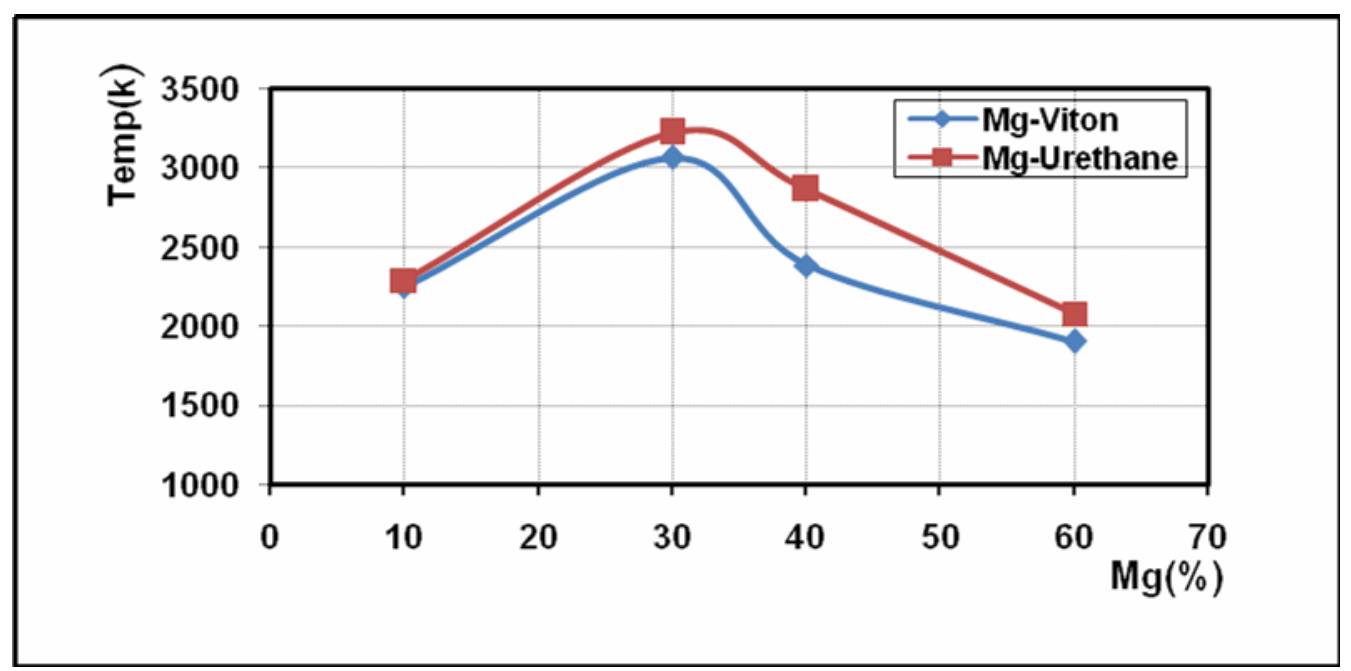

Fig.2. Type of binder effect on flame temperature.

\subsection{Flare compositions with Different percentage of binder.}

Many calculations have been carried out for many metal/Teflon compositions with different percentage of binder (viton) fig. 3. As can be shown adiabatic flame temperature have a slight change occurred with varying the percentage of Viton. These Due to the highly energetic of (viton) as it contain high percentage of (C.F) atom and these illustrate the flame temperature stability even the decrease in the percentage of Teflon and increase the percentage of binder. 


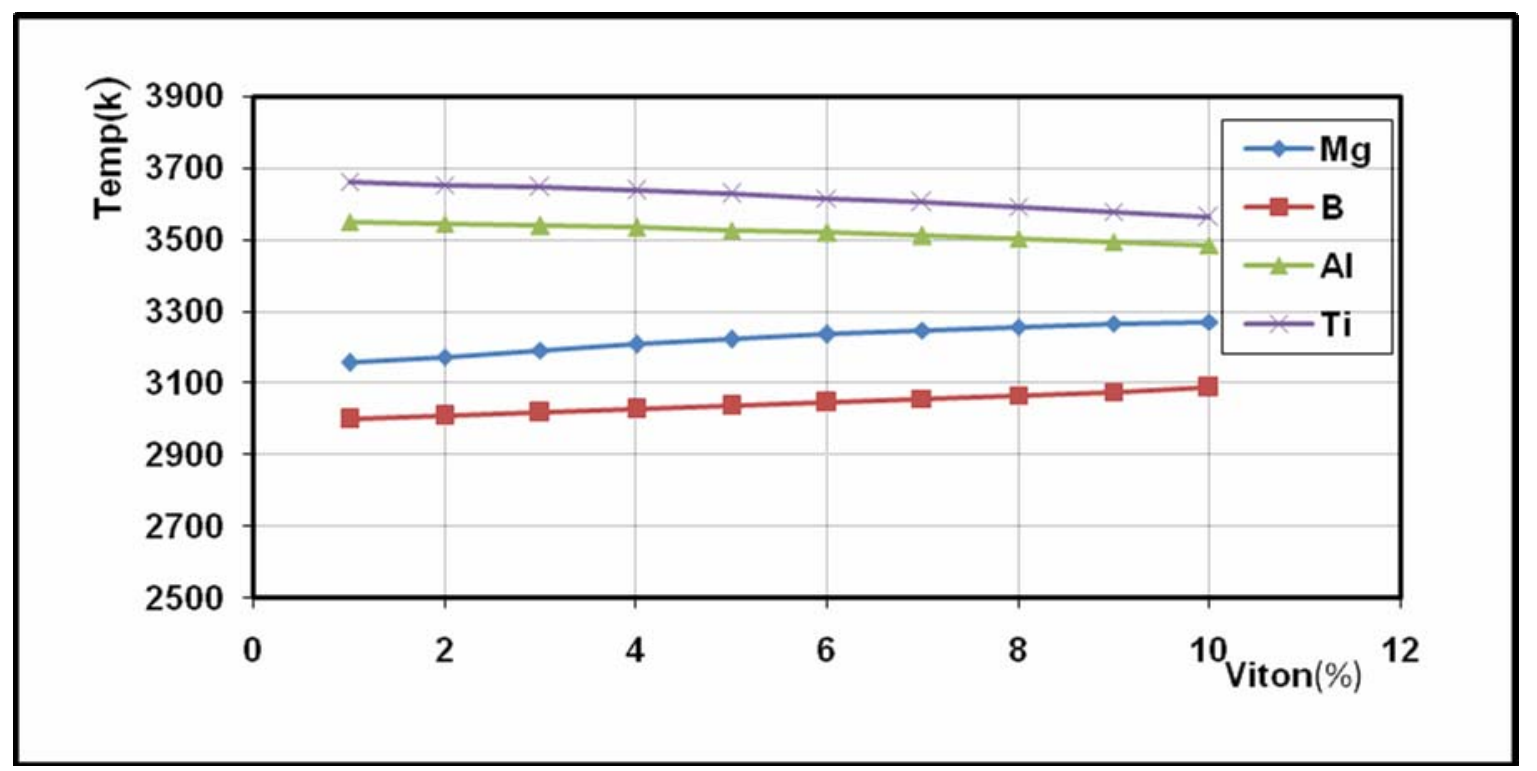

Fig.3. Binder percentage effects on flame temperature in metal/Teflon compositions.

\subsection{Flare compositions with Different Applying pressure}

The effect of the operating pressure has been examined through many calculations to different compositions with different atmospheric pressure to MTV (Mg/Teflon/Viton) Compositions fig. 4.

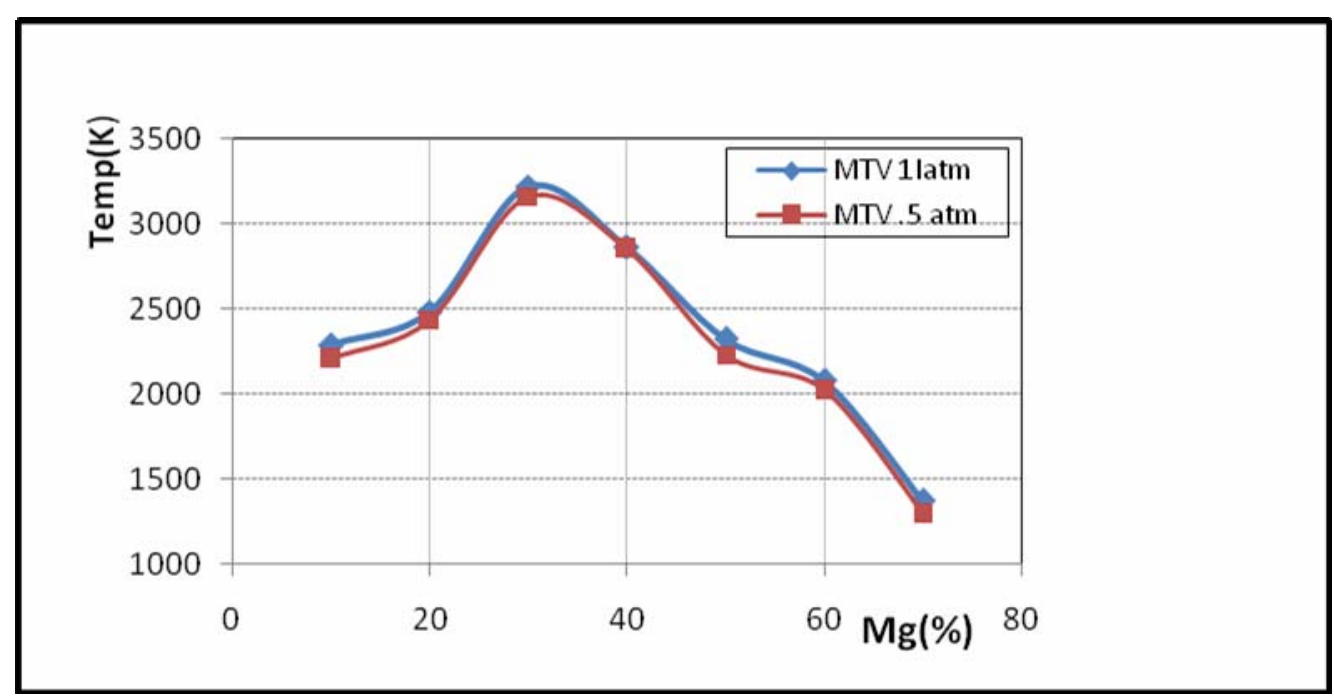

Fig.4. Pressure effect on flame temperature in MTV composition.

The results show that the differences in the surrounded pressure have no significant effect on flame temp and so the burning rate of the decoy flares compositions. In general view the height of the aircraft which cause decrease in pressure don't affect the flame temperature and burning rate of the pyrotechnic compositions. 


\section{CONCLUSIONS}

From this study it may be concluded that we can apply different metal fuel in decoy flare compositions taking into consideration that the highest flame temperature for metal/Teflon/viton compositions obtained at (30\% Mg), (30\% Al), $40 \% \mathrm{Ti})$, and $(10 \%$ B). High energetic binder like viton which maintain high flame temperature and so burning rate is preferable to use in compositions rather than moderate energetic binder as polyurethane. In addition, as the percentage of binder increase, flame temperature will increase for $\mathrm{Mg}$ and $\mathrm{B}$ and decrease for $\mathrm{Ti}$ and $\mathrm{Al}$, so the percentage of binder would be determined precisely. It was approved that the increase of the percentage of metal fuel has a great effect on flame temperature and so the emitted power which is the main factor that affect decoy flare against the incoming missile.Finally metal/ Teflon compositions which have high flame temperatures can be uses not even in decoy flare composition but also as igniter in solid rocket propellant ${ }^{[8]}$, The general conclusion may be that the ratio between metal fuel and Teflon is important but not sufficient to determine the optimum compositions of decoy flare charges.

\section{REFERENCES}

[1] A. Bailey and S. G. Murray, "Explosives, Propellants \& Pyrotechnics", BRASSEY'S, Volume 2, (1989).

[2] Ernst-Christian Koch "Review on pyrotechnic aerial infrared decoys", Propellants, Explosives, Pyrotechnics 26, 3-11(2001).

[3] Farid C.Christo " Thermochemistry and kinetics model for magnesium/Teflon/viton pyrotechnic composition"(1999)

[4] Ahmed,Azam "Ir laser guidance and image tracking systems and their passive counter measures"(2001)

[5] E-C.Kock, Metal/fluorocarbon pyrolants,III,developments and application of Magnesium/Teflonn/Viton(MTV), Propellants, Explosives, Pyrotechnics $.27,262,2002$.

[6] T.Kuwahara,S.Matsuuo,N.Shinozaki "Combustion and sensitivity characteristics' of Mg/TF pyrolants" Propellants, Explosives, Pyrotechnics, 22, pp 198-202, 1997.

[7] Curtis Selph "Chemical Equilibrium Specific Impulse (Isp) Code " (1991)

[8] A Göcmez, G Yilmaz, F Pekel and S Özkar " Development of MTV Composition as Igniter for HTPB/AP Based Composite Propellants", Propellants, Explosives, Pyrotechnics 24, 65-69 (1999). 